\title{
Identifying Key Residues That Drive Strong Electrostatic Attractions between Therapeutic Antibodies
}

Glenn M. Ferreira ${ }^{1}$, Hassan Shahfar ${ }^{1,2}$, Hasige A. Sathish ${ }^{3}$, Richard L. Remmele Jr. ${ }^{4}$, Christopher J. Roberts ${ }^{1 *}$

${ }^{1}$ Department of Chemical and Biomolecular Engineering, University of Delaware, Newark, DE 19716

${ }^{2}$ Department of Physics and Astronomy, University of Delaware, Newark, DE 19716

${ }^{3}$ AstraZeneca, Gaithersburg, MD 20878

${ }^{4}$ RemSciBiothera, Inc., Camarillo, CA 93012

\section{Supplemental Information}

(A)

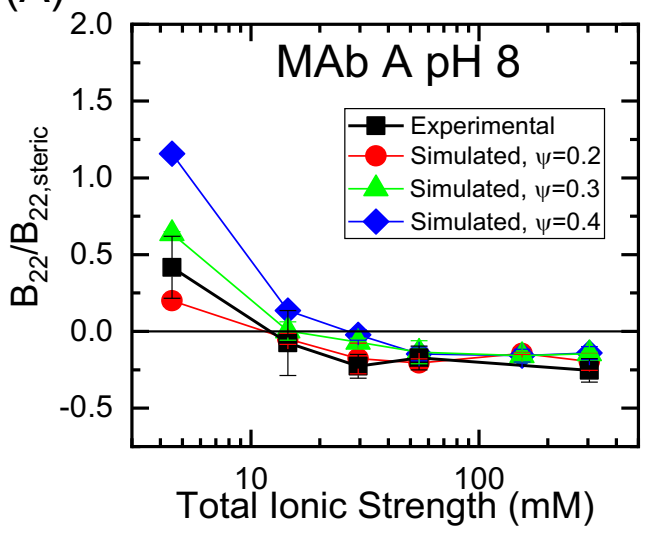

(C)

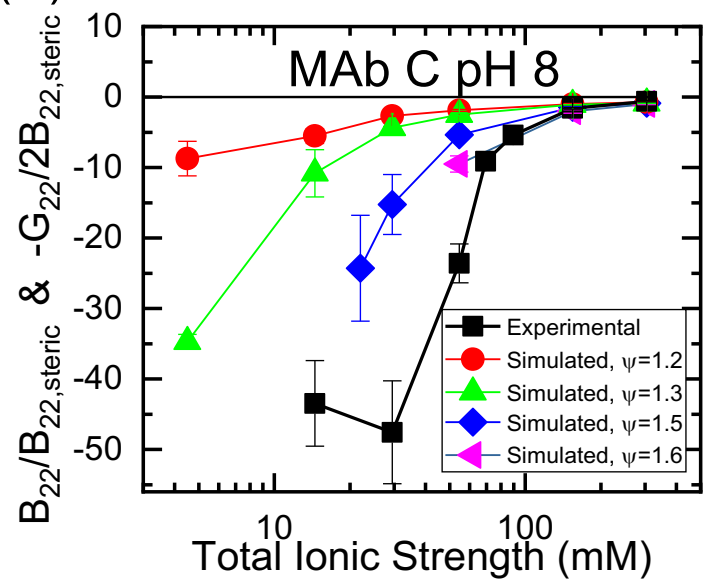

(B)

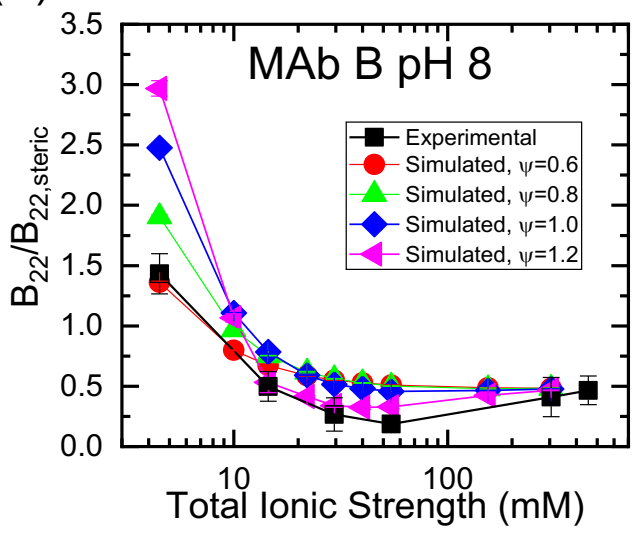

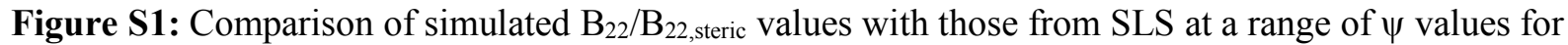
$\mathrm{pH} 8$ with MAb A (A), MAb B (B), and MAb C (C). Error bars represent 95\% confidence intervals for regressed $B_{22} / B_{22 \text {,steric }}$ or $-G_{22} / 2 B_{22 \text {,steric }}$ for the SLS values. Some MAb C SLS measurements are too

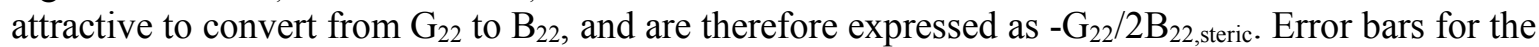
simulation results represent the standard deviation of at least three independent simulations. Connecting lines are only guides to the eye. (J. Pharm. Sci. 2019, 108, 120-132) 


\begin{tabular}{|c|c|c|}
\hline Domain & All Residue Index & Chargeable Residue Index \\
\hline MAb A \& C V $V_{L}$ & $1-111,664-774$ & $1-17(\mathrm{~A}), 1-15(\mathrm{C})$ \\
\hline $\mathrm{MAb} A \& \mathrm{C} \mathrm{C}_{\mathrm{L}}$ & $112-216,775-879$ & $18-40(\mathrm{~A}), 16-35(\mathrm{C})$ \\
\hline $\mathrm{MAb} A \& \mathrm{C} \mathrm{V}_{\mathrm{H}}$ & $217-337,880-1000$ & 41-64 (A), 36-61 (C) \\
\hline $\mathrm{MAb} A \& \mathrm{C} \mathrm{C}_{\mathrm{H}} 1$ & $338-448,1001-1111$ & $65-81(\mathrm{~A}), 62-79(\mathrm{C})$ \\
\hline $\mathrm{MAb} A \& \mathrm{C} \mathrm{C}_{\mathrm{H}} 2$ & $449-560,1112-1223$ & $82-110(\mathrm{~A}), 80-108(\mathrm{C})$ \\
\hline $\mathrm{MAb} \mathrm{A} \& \mathrm{C} \mathrm{C}_{\mathrm{H}} 3$ & $561-663,1224-1326$ & $111-133(\mathrm{~A}), 109-131(\mathrm{C})$ \\
\hline $\mathrm{MAb} \mathrm{B} \mathrm{V_{L }}$ & $1-113,662-774$ & $1-15$ \\
\hline MAb B C $C_{L}$ & $114-217,775-878$ & $16-35$ \\
\hline MAb B V & $218-337,879-998$ & $36-58$ \\
\hline MAb B C $\mathrm{H}_{\mathrm{H}} 1$ & $338-447,999-1108$ & $59-75$ \\
\hline $\mathrm{MAb} \mathrm{B} \mathrm{C} 2$ & $448-557,1109-1218$ & $76-105$ \\
\hline $\mathrm{MAb} \mathrm{B} \mathrm{C} \mathrm{C}_{\mathrm{H}} 3$ & $558-661,1219-1322$ & $106-128$ \\
\hline
\end{tabular}

Table S1: Lookup table providing the location of each domain within the sequence in terms of the all residue index as well as an index just including chargeable residue (Asp, Glu, His, Lys, Arg). All five chargeable residues were included in the index regardless of $\mathrm{pH}$ level (i.e. the index is consistent at $\mathrm{pH} 5$ and 8). 

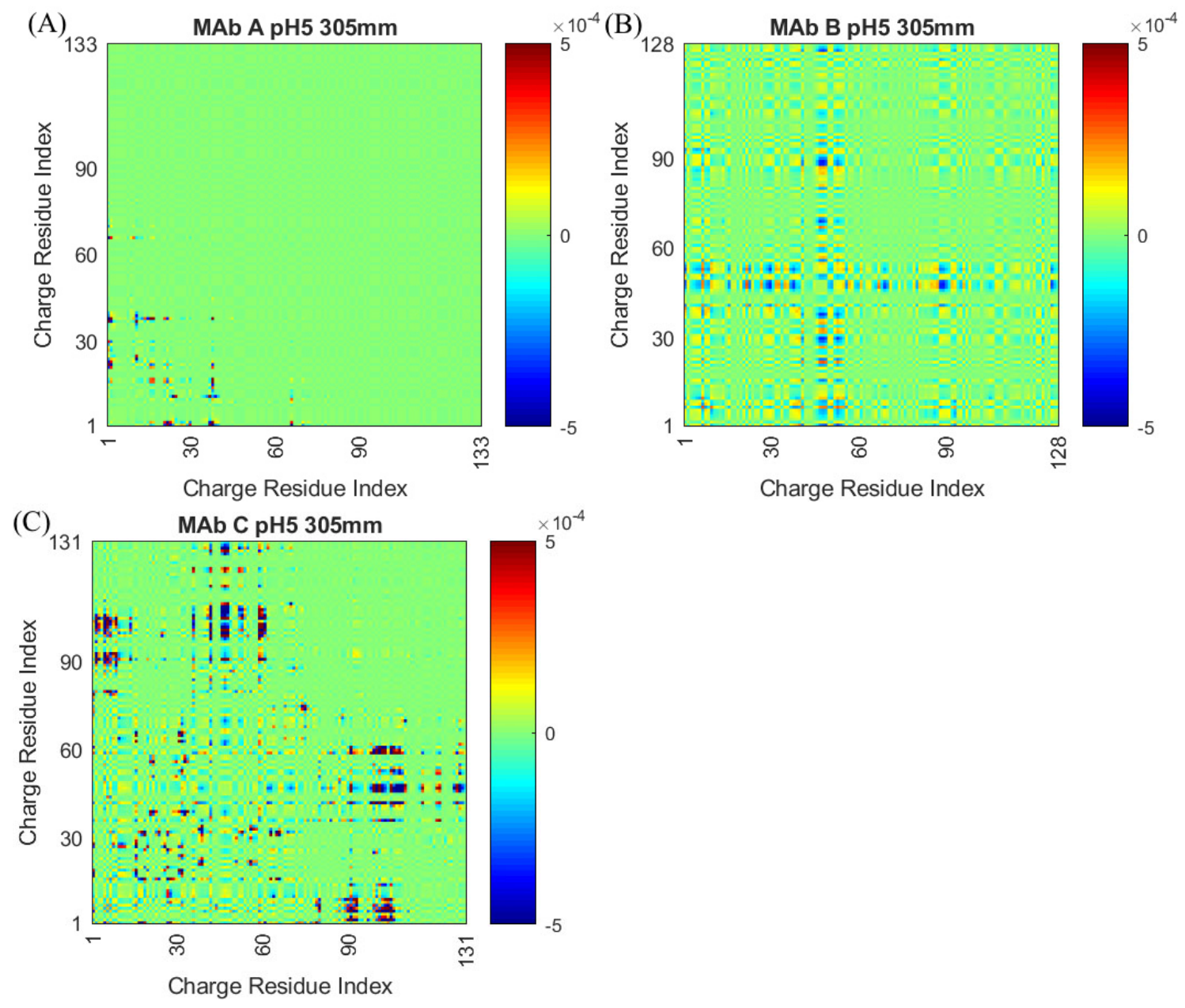

Figure S2: Pairwise interaction energies $\left(\tilde{\phi}_{i j}\right)$ between charged residues at $\mathrm{pH} 5$ at $305 \mathrm{mM}$ TIS for MAb A (A), B (B), and C (C) with Mayer weighting. The color corresponds to the interaction energy in units of $\mathrm{k}_{\mathrm{B}} \mathrm{T}$. Repulsions are shown in red. Attractions are shown in blue. Intermediate colors range between the repulsive and attractive limits as specified by the color bar. Color scaling is consistent across

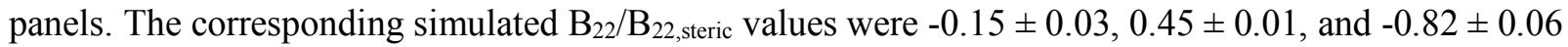
for $\mathrm{MAb} \mathrm{A}, \mathrm{B}$, and $\mathrm{C}$ respectively. 


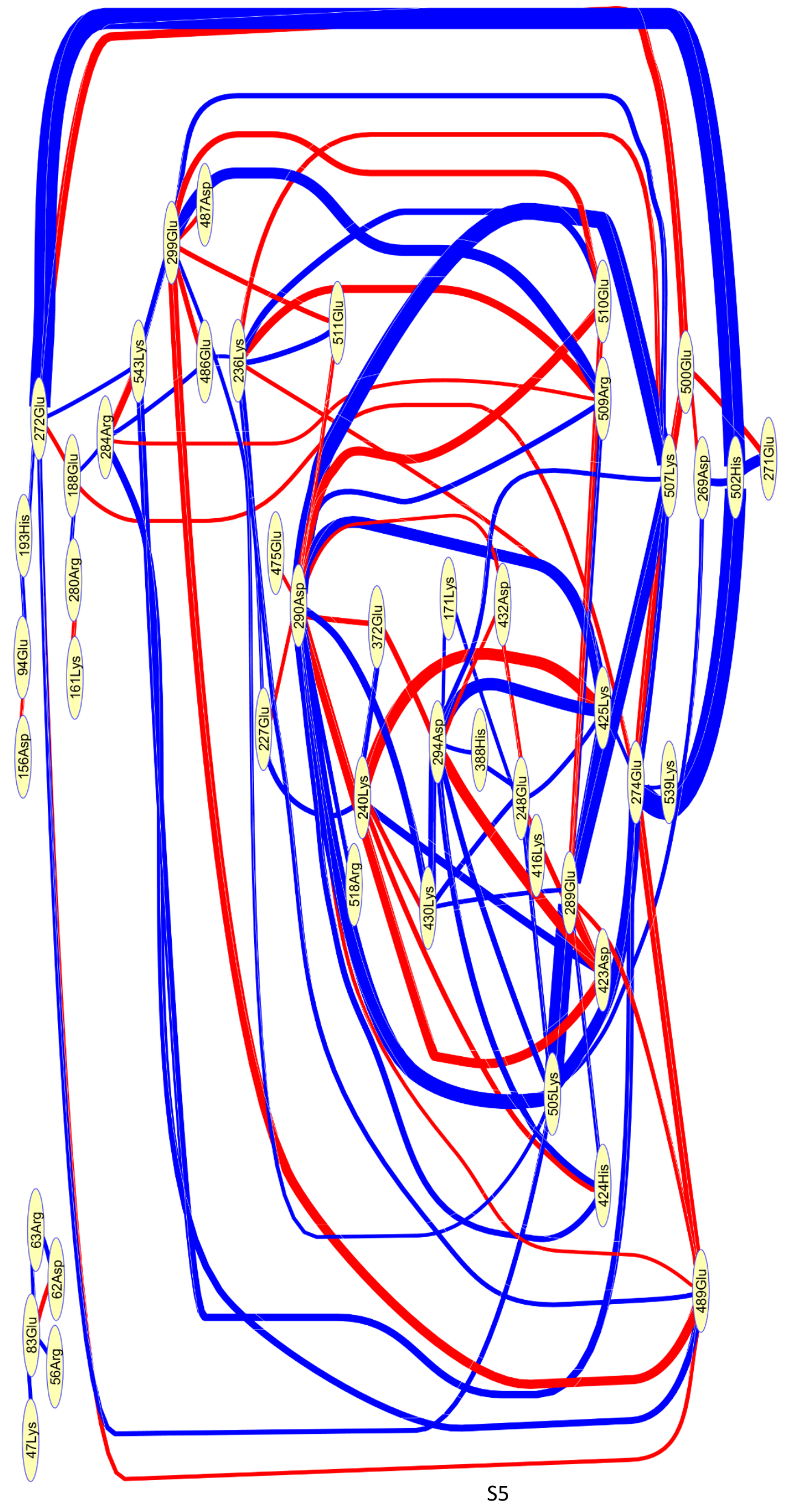

1

$<$

6 


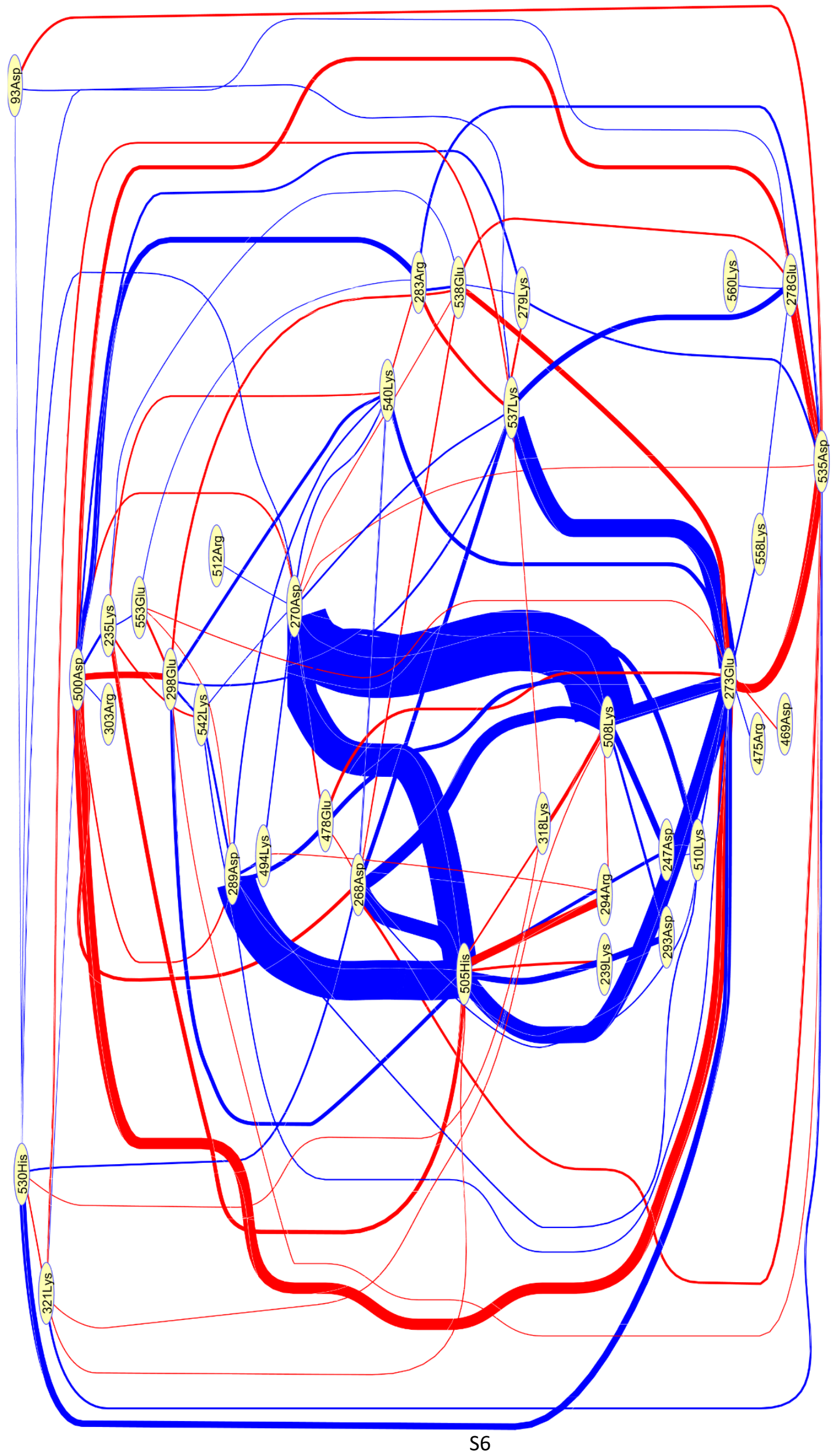



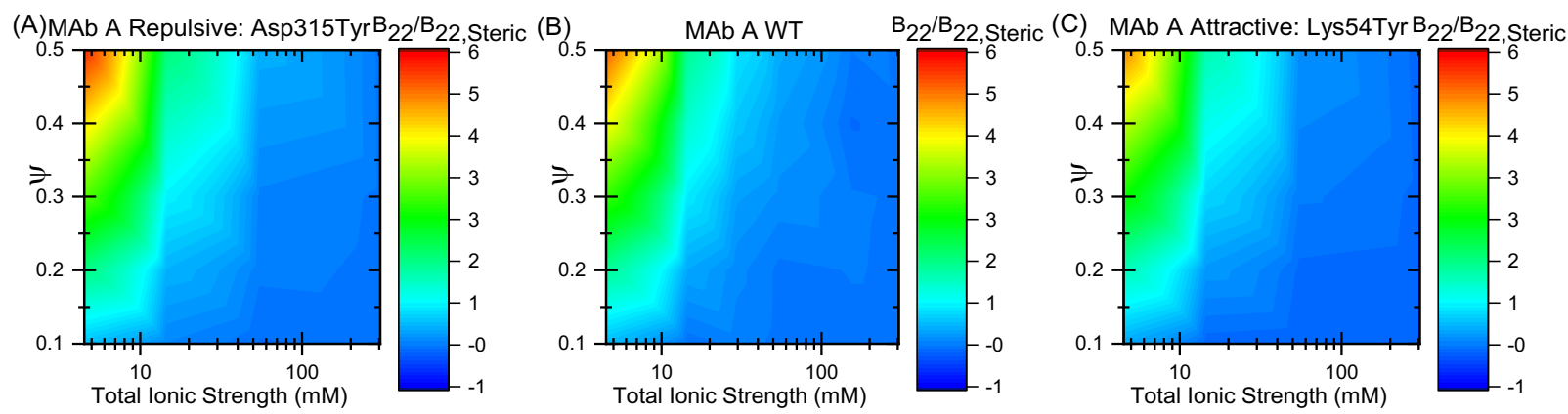

Figure S6: Comparison of $\mathrm{B}_{22}$ surface-response diagrams for MAb A wildtype and selected mutations at $\mathrm{pH}$ 5. Surface plots are for $\mathrm{B}_{22}$ as a function of TIS and $\psi$ for the most repulsive (panel A) and attractive (panel C) charge-to-neutral point mutation compared against the wild-type MAb (panel B). The color

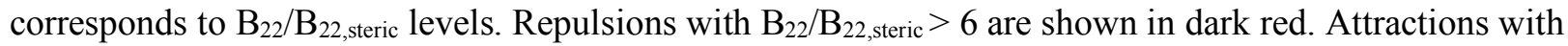
$\mathrm{B}_{22} / \mathrm{B}_{22, \text { steric }}<-1$ are shown in dark blue.
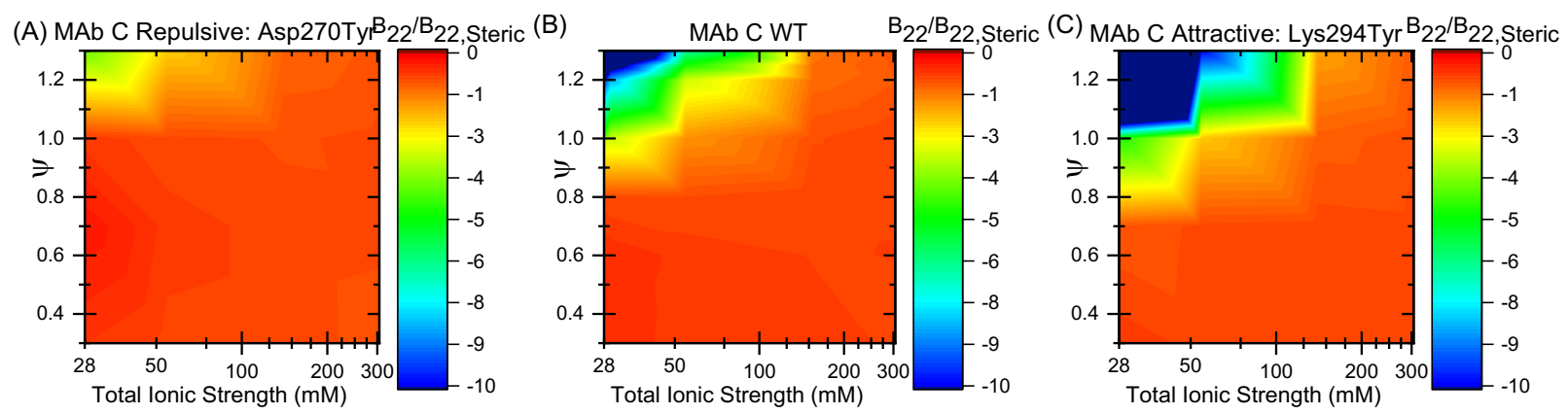

Figure S7: Comparison of $\mathrm{B}_{22}$ surface-response diagrams for MAb $\mathrm{C}$ wildtype and selected mutations at $\mathrm{pH}$ 5. Surface plots are for $\mathrm{B}_{22}$ as a function of TIS and $\psi$ for the most repulsive (panel $\mathrm{A}$ ) and attractive (panel C) charge-to-neutral point mutation compared against the wild-type MAb (panel B). The color

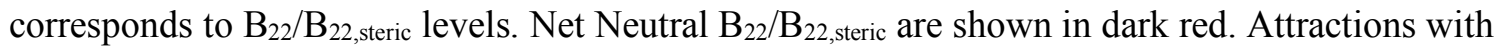
$\mathrm{B}_{22} / \mathrm{B}_{22, \text { steric }}<-10$ are shown in dark blue. 